\title{
Computer-supported experiential learning (Phase One - staff development)
}

\author{
Alan Staley and Diana Eastcott \\ Learning Methods Unit, University of Central England in Birmingham, \\ email:alan.staley@uce.oc.uk
}

The Computer-Supported Experiential Learning Project has been established to promote the use of communication and information technologies for teaching and learning within a vocational university. Phase 1 has concentrated upon raising awareness and actively involving academic staff in experiencing these technologies. The project is curriculum-led, and considers how technology can be applied appropriately to an established curriculum model which links theory and practice (Kolb, 1984). All academic staff were invited to take part by logging onto the university intranet, accessing information about teaching and learning, trying out ideas and emailing their online mentors with their plans and reflections. In addition, all staff could take part in discussion forums concerning a range of issues. The participation of academic staff is reported; which staff registered as having visited the site, which staff actively used the information to experiment with their teaching, and which staff took part in public online discussions. Barriers which limited participation are also reported. The outcome of Phase 1 has been to encourage over 40 academic staff to embed the use of learning technologies in their own course modules in Phase 2 with continued support from the Learning Methods Unit.

\section{Introduction}

In recent years the University of Central England in Birmingham has made considerable investments in developing computer networks. Developments have been technology-led, and the major use of the network has been for administration. The Computer-Supported Experiential Learning Project has been designed to refocus upon the curriculum, and to encourage academic staff to use the network technologies for teaching and learning. The broad aim of the project is to investigate and systematically evaluate the appropriate use of technology to improve the quality of learning.

\section{The curriculum model}

The theoretical framework for the research is a well-established curriculum model developed by Kolb (1984) which links theory and practice (see Figure 1). This model is relevant in a range of 


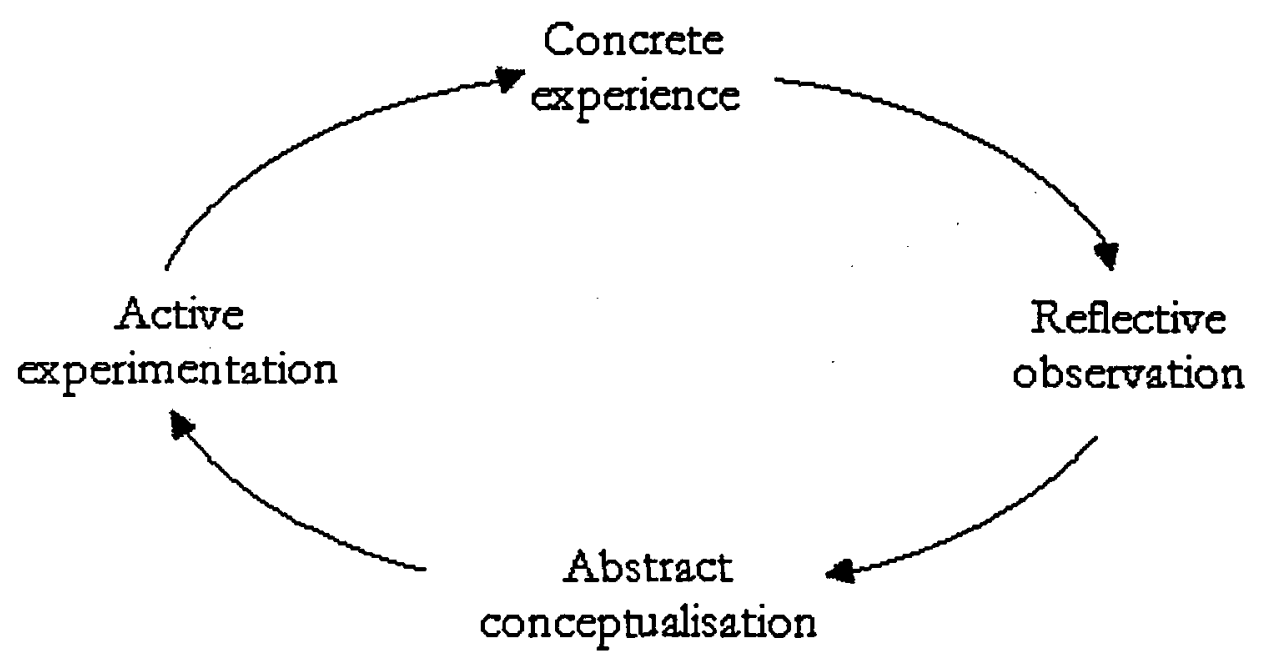

Figure 1:The Kolb Learning Cyde

educational contexts from continuing professional development to vocationally orientated undergraduate courses. It has been used effectively by the authors of this paper on a wide range of staff development programmes.

The crucial elements of this model are the links it makes between theory and practice; or, in the words of Kolb, between 'concrete experience' and 'abstract conceptualization'. It is common for university courses to be described as either practical or theoretical. Similarly, it is often said that theories are taught at university but 'real' learning is what happens out in the workplace. However, it is not sufficient just to have an experience in order to learn. Equally, it is not sufficient simply to learn new concepts. This learning must be tested out in new situations. The learner needs to make the link between theory and action by planning for that action, carrying it out, and then reflecting upon it, relating what happens back to the theory.

Experiential learning in the context of the model designed by Kolb involves a systematic, cyclical sequence of learning activities. The cycle may be entered by the learner at any point, but its stages must be followed in sequence. The interesting pedagogical issue is to develop appropriate learning and teaching strategies at each stage of the cycle. In other words, to provide structures which help learners to link theory and practice.

The 'reflective observation' and 'active experimentation' stages of the cycle are crucial. Reflective observation is the process of reflecting on an experience and making sense of it. Based on the work of Schon (1987) on the reflective practitioner, this stage of the learning cycle acknowledges the complexity of professional working practices where each decision is made in relation to the individual's own repertoire of examples, values, commitments and knowledge. In reality, reflection overlaps with the 'abstract conceptualization' stage of the cycle where new ideas and knowledge help the learner to have insights and to understand situations in a different 
way. The active experimentation stage of the cycle is the point where the learner plans how to make the link between theory and action. Concrete experience is therefore the practice of trying out the ideas in the workplace.

The stages of the cycle are by no means clear-cut. Considerable overlap can occur, as noted above. Work on learning styles (Kolb, 1974; Honey and Mumford, 1986) indicates that just as there is seen to be a division between theory and practice in education, so individuals may have particular preferences in their learning. Distinct styles of learning associated with the four stages of the experiential learning cycle have been identified, some learners being stronger at the 'practical' aspects, others at the 'theoretical' part of the cycle.

\title{
Application of technology to the curriculum model
}

The application of Kolb's model to Phase 1 is described in terms of abstract conceptualization, concrete experience, active experimentation and reflective observation.

\begin{abstract}
conceptualization
Academic staff spend considerable time in lectures expounding facts, theories, and concepts to students that constitute the knowledge base of a subject. The effectiveness of lectures has often been questioned (Bligh, 1972; Gibbs, 1982), and it is suggested that precious time with students could be better spent elsewhere in the Kolb Cycle. A subject knowledge base can be constructed as a Web (or intranet) site that students access in their independent learning time. That is not to suggest 'discovery' learning, where students discover things for themselves in a haphazard way (e.g. surfing the net), but rather a focused pursuit of knowledge. Key to this pursuit of knowledge are the learning activities within the site that students must do for real in the concrete experience stage of the cycle. In this way, the students' learning is being 'driven' by activities and problems, as described by Boud (1991).
\end{abstract}

Elton (1996) has suggested that we should not always expect students to be intrinsically motivated by our subject, and that students' intrinsic motivation will improve as they gain a sense of achievement or progress. Therefore, it is suggested that this stage of the cycle could include some formative computer-assisted assessment (CAA), so that students can check their understanding of key issues before putting theory into practice.

\section{Concrete experience}

In the post-Dearing age of lifelong learning it seems likely that work-based learning will grow, and links between theory and practice will need to be more explicit. Experiencing 'real world' problems is crucial to this model, and it is envisaged that where possible learning activities embedded within the Web site can be performed in a working environment. Where this is not possible (as in many full-time undergraduate programmes) it is suggested that academic staff create 'substitute experiences' such as role-plays, mock courts, client briefings etc. In this way, class-contact time is shifting from conceptualizing to experiencing. Whilst the authors acknowledge that some experiences can be simulated by computer, this is considered to be a last resort, used only where real experiences are too dangerous, expensive, or not practical.

\section{Active experimentation and reflective observation}

It is at these stages of the cycle that computer-mediated communication (CMC) is of particular importance. In active experimentation students can email their online tutor or mentor concerning their plans for putting theory into practice. The online tutor can individually guide and 


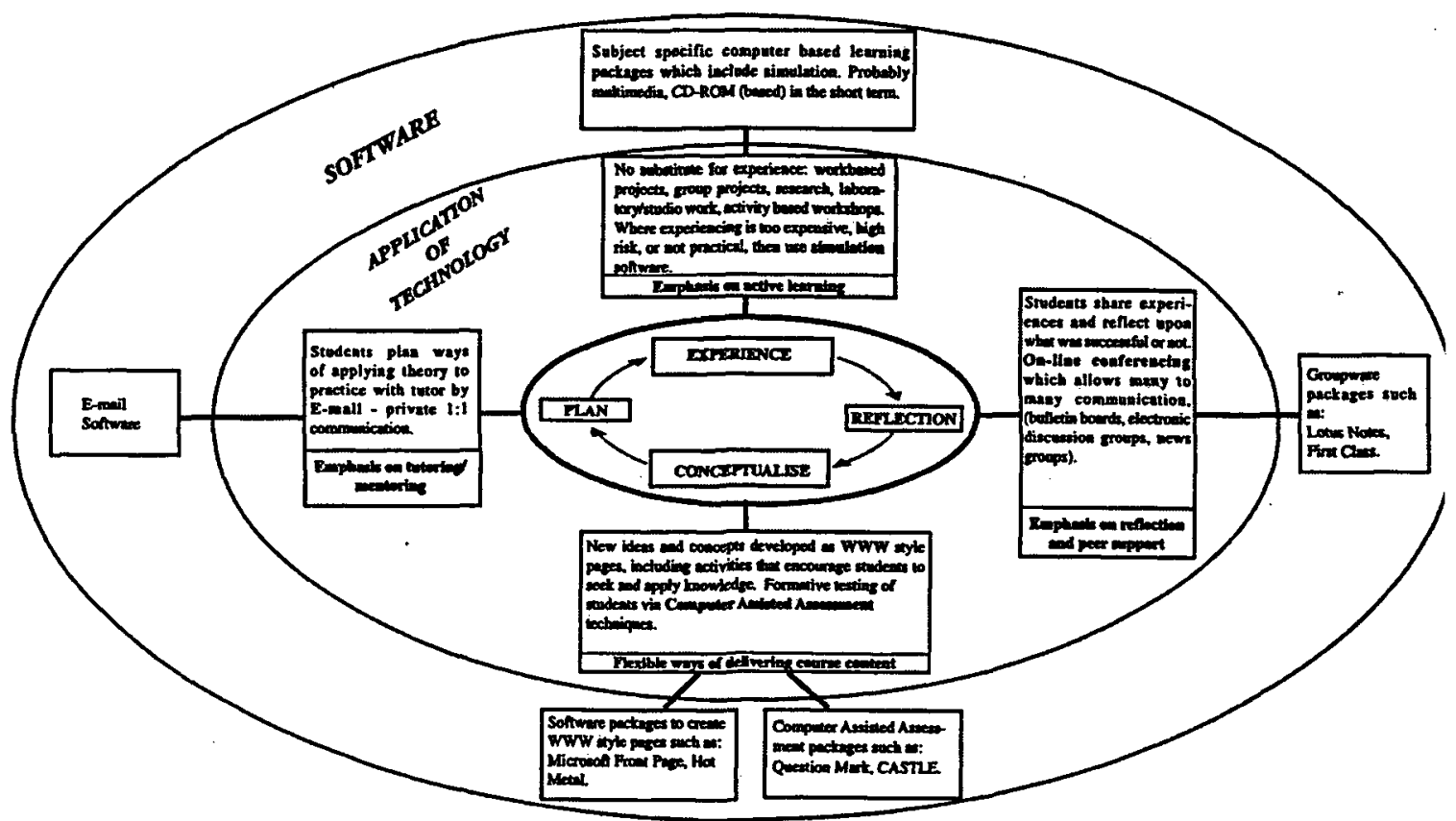

Figure 2: A model for applying learning technology to the experiential learning cycle

support students, offering advice, warning of pitfalls, and generally helping those students that cannot see a way forward. Reflective observation is well suited to online conferencing, where groups of students can work co-operatively to reflect upon how the theories worked in practice, and how the different contexts in which students have been.working have influenced this. Online conferencing is particularly suited to this, due to its asynchronous nature, which gives students time to think and make a considered contribution, unlike many face-to-face communications (McConnell, 1994). The member of academic staff is now functioning as a group facilitator as opposed to an individual mentor.

In summary, several technologies are being suggested, each having a specific purpose and place in the cycle. This is illustrated in Figure 2.

\section{Instigating organizational change}

Rather than simply telling academic staff about this model, it was decided that all academic staff within the University should have opportunity to experience it for themselves. An intranet site was developed using Microsoft Front Page, that contained ideas and theories about teaching, learning and learning technology. This included practical activities and small-scale experiments that staff could try out for real in their classes, i.e. putting theory into practice. The site also contained email links to a team of online mentors who could be contacted for help and support. All staff visiting the site were initially asked to register their name and faculty. Staff were also given the opportunity of taking part in several online discussion forums, one designed to reflect upon their experiments, and several others such as 'Rumours Central', created purely to entice staff into using the technology. This phase of the project lasted fifteen weeks, after 
which all staff not taking part were sent a questionnaire to establish the reasons for not participating, and their attitudes to learning technologies.

\section{Participation}

In total 59 staff participated in the project to some extent. For some, this simply meant browsing the site and registering. Others went on to use the online mentoring facility or discussion forums. Analysis of the questionnaire revealed that another 30 staff visited the site but did not register.

The participants were from all faculties that have access to the network, indicating wideranging interest in using learning technologies. The Vice-Chancellor and one Pro-ViceChancellor participated, revealing senior management commitment. However, only three managers (Deans, Associate Deans, Heads of Departments, and Heads of Schools) participated. All other participants were lecturing staff.

Anecdotal evidence suggests that it is the younger staff that are attracted to learning technologies, and older staff demonstrate resistance to new technologies and changing work practices. This project did not substantiate this, as there was no significant difference between the ages of those staff that participated, and those that did not. A gender bias did emerge though, as only 18.6 per cent of the participants were female, in a target population that was 39.8 per cent female.

Very few staff used the online mentoring facility to assist putting theory into practice, although there was considerable dialogue with one member of staff who was redesigning a course module. Many staff went straight to the discussion forums, and what follows is an analysis of these. It can be clearly seen from Figure 3 that although staff started to participate as soon as the project started, this soon diminished, reaching a low during Easter. Readvertising the project with a sample of a 'rumours' discussion including a response from the Vice-Chancellor provoked more response, but without doubt the greatest level of participation occurred after 'Learning Technology Week', a week of awareness-raising events that brought staff together face-to-face.

This pattern of participation demonstrates the nature of online conferencing. Clearly, interest wanes and, unless there is some personal value to be obtained, participation will drop. Staff had no motive to participate other than curiosity; there was no assessment or certification to encourage participation. It is also worth noting how the face-to-face events generated interest and raised motivation.

An analysis of discussion entries per member of staff revealed that the discussions were dominated by one of the authors and a small group of staff. This pattern is similar to face-toface discussions, with a small number of students frequently dominating events (Gibbs, 1992). While most staff only posted one or two messages (a tentative foray into the online world), some staff really got involved. In several instances, these staff were not academic staff, but technical support staff who had found out about the project and instantly realized the application to their area. Hence the 'technical queries' and 'intranet developments' discussion forums developed nicely. The discussion forum concerning teaching and learning issues was less spontaneous and needed considerable prompting from the authors. The rumours discussion forum was also slow to develop, with staff tending to read contributions but being reluctant to add new ones. The greatest discussion in the rumours forum followed an example given by the 


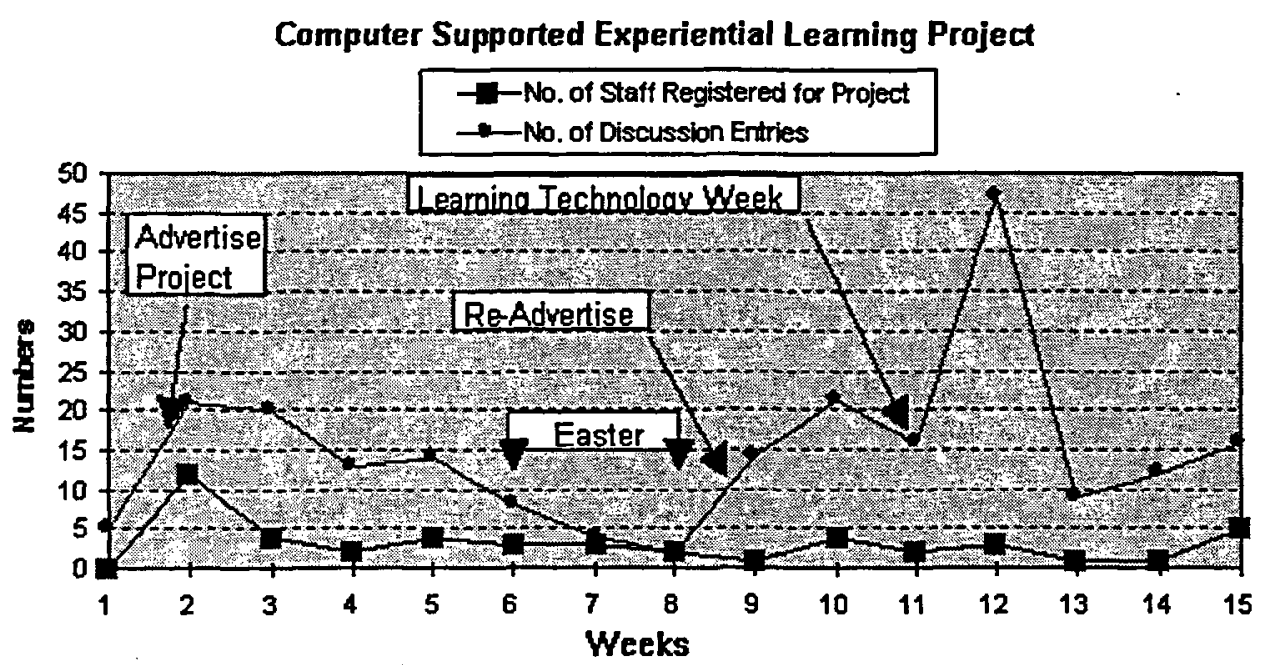

Figure 3: Participation in the Computer Supported Experiential Learning project over time.

Vice-Chancellor of what a rumour might look like as a way of introduction - 'Is it true that staff at Perry Barr will be charged $£ 100.00$ per year to use the car park from September?' Clearly, whilst many of these discussions were light-hearted, they did entice staff to use the technology.

Of the staff that did not participate in the project, 26.7 per cent completed a questionnaire designed to establish their views on leaming technology. The major reason for not taking part in the project was time (73.6 per cent of respondents). One respondent in particular expressed the time demands that are placed upon academic staff:

Too busy with full teaching, research, and admin load + HEFC + course revalidation + new course developments.

One barrier to the uptake of learning technology is therefore time, especially when one considers the 'up-front' investment in time that learning technology demands. Other barriers included problems of access to, and reliability of, the technology.

Only 9 per cent of respondents indicated that they were not interested in the project, and the attitude to learning technology was very encouraging. Few staff considered that their careers are threatened by the technology. Most staff were interested in applying the technology to their teaching and learning and believed that learning technology would enhance the quality of student learning. The only other barrier that was identified was that of technical support, which is aptly summed up by one respondent:

... this creates a huge barrier to encouraging me to do anything involving technology in my teaching and learning. If the IT environment improved, and the support culture existed, I would get more involved. At present, I bang my head against a brick wall.

\section{Outcomes}

Phase 1 of the project has raised awareness, and actively involved academic staff in using learning technology applied to an established curriculum model. It has encouraged 
approximately 40 staff to embed the use of learning technology in their own course modules in Phase 2 of the project. Training and support of the Learning Methods Unit will continue during this phase. Phase 2 will evaluate fifteen learning technology projects across most faculties in the university.

\section{References}

Bligh, D. (1972), What's the Use of Lectures?, Penguin.

Boud, D. (1991), The Challenge of Problem Based Learning, London: Kogan Page.

Elton, L. (1996), 'Strategies to enhance student learning: a conceptual analysis', Studies in Higher Education, 21, 57-68.

Gibbs, G. (1982), Twenty Terrible Reasons for Lecturing, Standing Conference on Educational Development.

Gibbs, G. (1985), Learning by Doing - A Guide to Teaching and Learning Methods, London Further Education Unit.

Gibbs, G. (1992), Discussions with More Students, The Polytechnics and Colleges Funding Council.

Honey, P. and Mumford, A. (1986), The Manual of Learning Styles, Maidenhead: Peter Honey.

Kolb, D. A. (1984), Experiential Learning - Experience as the Source of Learning and Development, New Jersey: Prentice Hall.

Kolb, D. A., Rubin, I. M and McIntyre, J. M. (1974), Organisational Psychology, an Experiential Approach, New Jersey: Prentice Hall.

McConnell, D. (1994), Implementing Computer Supported Cooperative Learning, London: Kogan Page.

Schon, D. A. (1987), Educating the Reflective Practitioner, London: Jossey Bass. 